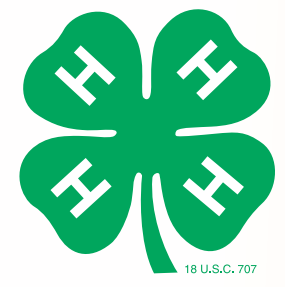

\title{
Online Learning Fact Sheet for the 4-H Youth Development Program Supporting Productive Educator Practices for Out-of-School Time
}

STEVEN M. WORKER, 4-H Youth Development Advisor, UC Agriculture and Natural Resources
$\mathrm{O}$ nline learning environments may provide opportunities for youth to learn, grow, and practice around a subject matter that are similar to the opportunities provided in physical learning environments. Youth development programs are well positioned to foster innovation for online learning.

Teaching during out-of-school time differs from teaching in formal school environments. In out-of-school time, youth participation is voluntary, based on youth interest, and anticipated outcomes emphasize socio-emotional and youth development indicators just as much as knowledge and skills. Teaching during out-of-school time requires educators to become coaches, mentors, facilitators, and partners.

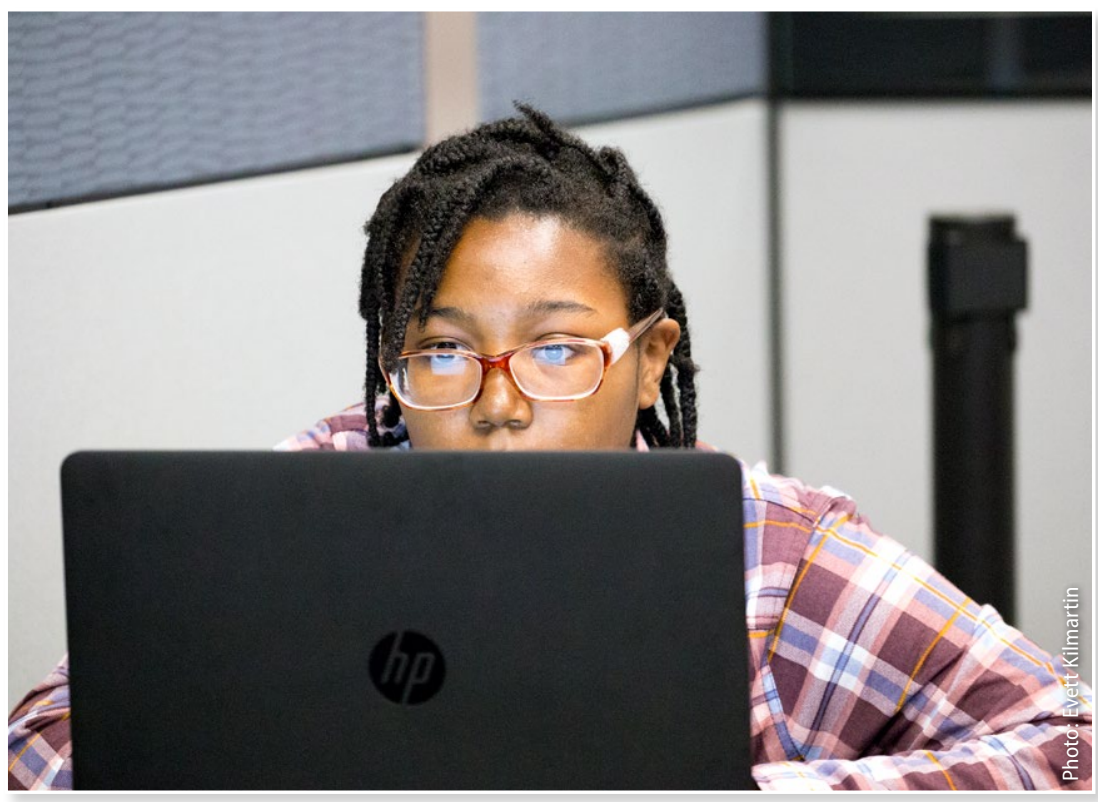

For online learning during out-of-school time, educators must continue to plan program goals and a sequence of learning experiences, employ experiential education, and promote positive youth development. Educators not familiar with online learning may experience apprehension or confusion over the choice of technology, and the process of planning a blended approach of synchronous (real-time) and asynchronous (between meetings) learning activities. Fortunately, there is more in common than there is divergence between in-person learning and online learning (Boettcher and Conrad 2016):

- Every structured learning experience has four elements: the youth at the center of the learning experience, the educator, the core concepts/learning objectives/curriculum, and the context/learning environment.

- Learners bring their own knowledge, skills, and attitudes to a program.

- Youth do not need to learn all the program content, just the core concepts.

- There is always a learning environment. The online environment might be a home, library, or coffee shop. The educator has less control over the online learning environment so must plan activities and learning experiences accordingly.

- The more time youth participate, the more they will learn and grow.

The following pages offer best practices and examples of activities for teaching online during out-of-school time. 


\section{Three key points for online learning}

\section{Teaching methods first, technology second}

The emphasis needs to be planning program goals with an engaging sequence of group and individual activities taking place in real-time and between meetings. Selection of technology tools should come second.

\section{Involve youth in choices of digital tools}

Young people often have experience in digital tools, media, and websites. Tap into their expertise and invite them to offer options, and together as a full group select digital tools to enhance the learning experience.
Focus on relationships

Youth-adult relationships are an essential part of out-of-school time programs. Youth need positive, sustained, and trusting relationships with caring, competent, and committed adults, in an in-person program or an online program.

\section{Examples of activities for online learning}

\begin{tabular}{|c|c|c|}
\hline Group size & Synchronous (real-time) & $\begin{array}{l}\text { Asynchronous } \\
\text { (between meetings) }\end{array}$ \\
\hline Individual & $\begin{array}{l}\text { - Invite youth to make a presentation. } \\
\text { - Ask youth to rotate facilitation roles. }\end{array}$ & $\begin{array}{l}\text { Educator provides an activity for youth to } \\
\text { complete at home, either by themselves or } \\
\text { with help from a parent or guardian. Youth } \\
\text { share their experience with the educator } \\
\text { through email/social media. }\end{array}$ \\
\hline Small group & \multicolumn{2}{|c|}{$\begin{array}{l}\text { - Small-group time may be allocated during real-time meetings, or youth can arrange to convene } \\
\text { between meetings. Assign a group project: pose a real-life issue or problem for youth to discuss } \\
\text { and pose solutions to. }\end{array}$} \\
\hline Large group & $\begin{array}{l}\text { - Hold meetings using audio-video technology. } \\
\text { Talk about a concept or conduct a } \\
\text { demonstration, facilitate a group discussion. }\end{array}$ & $\begin{array}{l}\text { Discussion board: educator and/or youth } \\
\text { post questions, view what others write, and } \\
\text { respond. } \\
\text { - Social media: youth post photos and videos } \\
\text { related to the subject matter; and review } \\
\text { comments from their peers. }\end{array}$ \\
\hline
\end{tabular}




\section{Promising practices for online learning during out-of-school time}

\section{Be present and create a supportive online community.}

- Educators should be present in three ways: (a) relationally, by creating connections with youth and becoming aware of their interests and abilities; (b) pedagogically, by facilitating the learning experience; and (c) cognitively, by supporting each young person as they develop knowledge and skills.

- Set norms for your meetings. Plan for plenty of time for youth-to-youth interaction; and plan informal conversation time perhaps before or after each meeting.

\section{Create group commitments.}

- Near the beginning, help the group create group commitments (aka ground rules). Particularly important to discuss is how often and through which ways everyone will communicate online and between meetings.

- Involve youth in discussions about technology norms; for example, how and when should everyone troubleshoot connections, what to do when someone is interrupted (e.g., by a barking dog, family member), and how should the group ensure all youth feel included, particulary those joining the meeting by audio (phone) with no video.

\section{Be intentional about promoting physical and mental health.}

- Plan for breaks to get youth up and moving, and break up long periods of everyone sitting behind a screen.

- Provide time for youth to share and talk with each other more informally, to help them feel cared about by others and feel a sense of connection to others in the group.

Use large-group, small-group, and individual activities in real-time (synchronously) and between meetings (asynchronously).

- Balance real-time (synchronous) full group meetings with individual (asynchronous) activities youth can do between meetings.

- Build opportunities for youth to participate as a member of a full group, in smaller groups, and individually for both synchronous and asynchronous learning.

\section{Reflect after each meeting; ask youth to provide feedback, too.}

- After each meeting, briefly reflect on what worked well, what did not work well, and what to do differently next time.

- Ask youth to provide their feedback, too, on their excitement, motivation, and experience.

\section{Combine core concept learning with customized and personalized learning.}

- Prepare learning objectives with associated core concepts in advance. Additionally, design options and choices within learning experiences that link the core concepts.

- As meetings progress, be flexible and allow youth to choose activities based on interest and ability. Or subsitute new activities that better align with young people's prior knowledge and interest.

\section{Bridge the digital divide.}

- Consider digital accessibility needs and work to identify alternative approaches to engage youth through nondigital means to the extent possible. This may include the educator and/or other youth/peers making phone calls or mailing materials to ensure those without access or with limited access are included. 


\section{Reference}

Boettcher, J. V., and R-M Conrad. 2016. The online teaching survival guide. 2nd ed. John Wiley \& Sons, Inc.: San

Francisco, CA.

\section{For Further Information}

For more UC ANR publications and products, visit our online catalog at https://anrcatalog.ucanr.edu/, call 1-800-994-8849, or write anrcatalog@ucanr.edu.

(C)2021 The Regents of the University of California. This work is licensed under the Creative Commons AttributionNonCommercial-NoDerivatives 4.0 International License. To view a copy of this license, visit https://creativecommons.org/ licenses/by-nc-nd/4.0/ or send a letter to Creative Commons, PO Box 1866, Mountain View, CA 94042, USA.

Publication 8697

ISBN-13: 978-1-62711-174-4
It is the policy of the University of California (UC) and the UC Division of Agriculture and Natural Resources not to engage in discrimination against or harassment of any person in any of its programs or activities. (Complete nondiscrimination policy statement can be found at https://ucanr.edu/sites/anrstaff/ files/215244.pdf.)

Inquiries regarding ANR's nondiscrimination policies may be directed to UCANR, Affirmative Action Compliance and Title IX Officer, University of California Agriculture and Natural Resources, 2801 Second Street, Davis, CA 95618, (530) 750-1343, titleixdiscrimination@ucanr.edu.

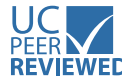

This publication has been anonymously peer reviewed for technical accuracy by University of California scientists and other qualified professionals. This review process was managed by UC ANR Associate Editor for 4-H Youth Development, Dorina Espinoza. 